\title{
Walking away: The embodied achievement of activity closings in mobile interaction
}

\author{
Mathias Broth and Lorenza Mondada
}

\section{Linköping University Post Print}

Tweet

N.B.: When citing this work, cite the original article.

Original Publication:

Mathias Broth and Lorenza Mondada, Walking away: The embodied achievement of activity closings in mobile interaction, 2013, Journal of Pragmatics, (47), 1, 41-58.

http://dx.doi.org/10.1016/j.pragma.2012.11.016

Copyright: Elsevier

http://www.elsevier.com/

Postprint available at: Linköping University Electronic Press

http://urn.kb.se/resolve?urn=urn:nbn:se:liu:diva-90682

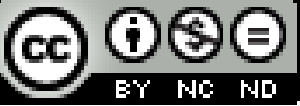




\title{
Walking away: The embodied achievement of activity closings in mobile interaction ${ }^{1}$
}

\author{
Mathias Broth ${ }^{\mathrm{a}}$, Lorenza Mondada ${ }^{\mathrm{a}, \mathrm{b}}$ \\ ${ }^{a}$ Department of Culture and Communication, Linköping University, Sweden \\ ${ }^{\mathrm{b}}$ Basel University, Switzerland
}

\begin{abstract}
In this paper we describe in detail the coordinated practices of walking away as reflexively contributing to the organization of activity closings. The paper contributes to conversation analytic studies interested in multimodality, space and mobility, by showing the relevance of walking for the systematic and situated organization of talk-in-interaction. More particularly, the paper deals with sequential environments in which activity closings are projected, and achieved by the participants; it shows that in this position, initiating walking away is a resource that makes closing publicly projectable and recognizable. Moreover, the study shows how walking away is a negotiated matter, being initiated by some, aligned or disaligned by others, possibly retracted and revised. Finally, the study demonstrates that walking away as a coordinated and negotiated practice raises normative expectations among the participants: a deviant case is discussed in which participants orient to the absence of such a coordination. In sum, the paper offers a detailed analysis of a particular multimodal practice -- walking -- as a conduct systematically coordinated with talk-in-interaction.
\end{abstract}

Keywords: Social interaction; Conversation analysis; Multimodality; Embodiment; Walking; Closings

\section{Introduction}

This paper is about the relevance of walking for the achievement of activity closings in human interaction. Movement through walking is shown to be mutually configured with the emergent organization of sequences within talk-in-interaction. Through a detailed analysis of video recordings of social interactions conducted in three languages (French, Swedish and English), and where participants walk from one place to another, we show how walking away can be used as a resource for achieving closings of activities.

The paper originates in the observation that, as conversational projects are brought to a close, participants often walk away in a coordinated way. Therefore, it investigates the relevance of such movement for the finely coordinated sequential organization of talk and embodied actions. We began our analyses wondering whether walking could contribute to the intelligibility of current talk. Indeed, could walking be a methodic embodied practice? And if so, could its systematicity be displayed in the service of particular interactional practices?

Our interest in walking is rooted in a broad view of embodied resources for interaction (section 2) and in the possibility that taking steps may substantially contribute to the organization of a particular sequential environment: closings (section 3). In this paper, we aim at demonstrating that, in mobile interactional encounters, walking away is initiated, conducted,

\footnotetext{
${ }^{1}$ Please refer to this article as: Broth, M, \& Mondada, L. (2013). Walking Away. The embodied achievement of activity closings in mobile interaction. Journal of Pragmatics 47(1), 41-58. Page numbers and page breaks correspond to published journal version. http://dx.doi.org/10.1016/j.pragma.2012.11.016

This work is licensed under the Creative Commons Attribution-NonCommercial-NoDerivs 3.0 United States License. To view a copy of this license, visit http://creativecommons.org/licenses/by-nc-nd/3.0/us/ or send a letter to Creative Commons, PO Box 1866, Mountain View, CA 94042, USA.
} 
managed, and possibly also repaired in systematic ways as an interactional practice central to the organization of social interaction.

\section{A broad way of considering multimodality and embodiment: walking}

Conversation analysis deals with the methodic ways in which participants organize social interaction. The very notion of 'method' comes from Garfinkel (1967), who shows that participants build the intelligibility of their action in an orderly (i.e. a 'methodic') and publicly recognizable ('accountable') way, which is both systematic and indexical, both transcending various contexts and taking into account their diversity (both context-free and context-shaped, Sacks et al., 1974:699; Heritage, 1984). This has prompted a general interest in the methodic practices and resources through which turn-taking and more generally coordinated actions are achieved in finely tuned ways. A range of resources have been explored -- concerning linguistic dimensions, such as syntax, prosody, and meaning (e.g. Ford et al., 1996), as well as embodied ones, such as gesture, gaze, head movements, nods, facial expressions and body postures (e.g. Goodwin, 1981; Heath, 1986).

In the methodic organization of turn-taking and sequences, the multimodal resources involved do not only concern grammar and gesture, but encompass a variety of other embodied aspects, all finely tuned in their mutual coordination. For example, Heath (1986) shows the importance of the coordination between gaze, body posture and body manipulations of both doctor and patient; Mondada and Schmitt (2010) the coordination of a range of multimodal resources, going from gesture to body positions, in interactional openings; Mondada (2009) and Hausendorf et al. (2012) the shaping of interactional space by the arrangement of the bodies; Goodwin and Goodwin (1996), Luff and Heath (1998) and Broth (2009) the local embodied adjustments to the complex ecology of the workplace; and McIlvenny et al. (2009), Haddington et al. (2013) and Broth et al. (forthcoming) the importance of considering mobile bodies in interaction. Goodwin's work (2000) stands as a prime example of this multimodal interactional perspective, showing that it is crucial to consider other 'semiotic resources' than those offered by speakers' talk and by participants' bodies, such as the environment and the material artefacts that surround interactants, out of which they build complex 'contextual configurations', which contribute to the production and interpretation of meaningful activities. What emerges from all these studies is the necessity to go beyond the analysis of single 'modalities' coordinated with talk, and take into consideration the broader embodied and environmentally situated organization of activities (Streeck et al., 2011).

Early work on walking already describes 'doing walking' as a methodic practice and a concerted accomplishment (Ryave and Schenkein, 1974:265). Members achieve 'walking together', being recognized both as a 'vehicular unit' (Goffman, 1971:8) and as 'withs' (Goffman, 1971:19). In walking together, participants organize their concerted action both within their group - maintaining proximity and pace, speeding up and slowing down, managing turns and stops together (see Allen-Collinson, 2006; Broth and Lundström, 2013; vom Lehn, 2013; De Stefani, 2010, 2012) -- and with respect to other passers-by - avoiding collisions, adjusting to the trajectory of others and making accountable their interruptions of their trajectory (Watson, 2005). Different mobile units can also converge, as when various individuals or groups meet and merge, thereby constituting one unique interactional space (Mondada, 2009). Conversely, people can also display that they are not in a 'with', exhibiting civil inattention and minimizing the effects of co-presence (Goffman, 1971; Sudnow, 1972). As noted by Ryave and Schenkein (1974), the fact that these challenges are resolved in unproblematic ways reveals “the nature of the work executed routinely by participant walkers”' (1974:267).

Moreover, collective walking activities are organized by being oriented in a finely tuned way to the organization of talk and even to the details of the emergent construction of turns: Relieu (1999) and Broth and Lundström (2013) show how turn design is sensitive to the spatial ecology encountered by speakers talking and walking; Mondada (2009) shows how the first turn of an encounter is finely designed with respect to the co-participants' walking bodies.

In this paper, we focus on the multimodal resources mobilized to accountably achieve sequence closings in co-present and embodied interactions. We integrate the consideration of body postures in walking, by showing that they achieve the visibility of closings: walking practices, such as walking away consideredhere, walking out(Llewellyn and Butler, 2011), or running away (Deppermann et al., 2010), emerge as oriented to transition-relevance places in talk (TRPs, Sacks et al., 1974) and to transitions from one activity to another. Conversely, they achieve the accountability of these transitions in a publicly visible way, so that all co-participants can align -- or perhaps disalign - with them in a temporally constrained monitor space thus opened.

\section{Closings in talk and embodied interaction}

How closings of conversations are achieved and co-ordinated is, since the seminal paper by Schegloff and Sacks (1973), a recurrent analytical topic in ethnomethodological and conversation analytic studies. In their paper, the “closing 
problem' (1973:290) is framed as a members' concern for how to get out of the normative expectation for a next turn after each new TRP, so as to close down an ongoing conversation in an orderly way. This prompted an interest in the verbal and prosodic resources for projecting and achieving closings, focusing on a wide range of phenomena, such as assessments (Antaki, 2002), prosodic formatting (Auer, 1990; Goldberg, 2004; Wright, 2011) and syntactic constructions (Pekarek Doehler et al., 2011). Attention has also been paid to how emergent closing sequences may be suspended in orderly and strategic ways (Button, 1987; Bolden, 2008).

This interest in closings has been extended in order to consider how co-present parties end their social interaction in various settings. Heath (1986) describes how doctor--patient interaction may be brought to an end in very close coordination, using embodied resources; LeBaron and Jones (2002) describe how participants deploy multimodal practices and orient to the material surround to organize the closing of a chance encounter in a beauty salon; De Stefani (2006) shows how customers visibly organize their leave-taking from the butcher's counter in a supermarket. Moreover, a series of studies have described the complex practices through which transitions from one activity to another are organized by mobilizing multimodal resources and artefacts (Modaff, 2003; Robinson and Stivers, 2001; Mondada, 2006; Deppermann et al., 2010).

Prior to the initiation of sequences leading to the closing of the entire conversational event, in telephone conversations as well as in co-present interaction, possible topic or sequence closures are routinely organized too (Schegloff and Sacks, 1973; Button, 1987). In fact, over the course of conversational events there are often many possible topic closures that never lead to the initiation of closings of conversations, but instead into the launch of a new topic or activity (Button and Casey, 1985). There are moments in interaction at which activities, communicative projects (Linell, 2009), tasks, topics or sequences are recognizably complete, and where a new activity, project etc. may be relevantly initiated, rather than, say, end a conversation. We will refer to such closings as 'activity closings'.

In this paper, we consider activity closings in co-present and mobile situations, i.e. where mobility is a relevant feature of the current activity, as in guided walks. A body of research is emerging that takes mobility into account in analyzing sequentially organized social interaction, stressing the mutually constitutive and sequential relations between movement through space and the on-line formatting of emergent talk and other bodily actions (Haddington et al., 2013; Broth et al., forthcoming). This paper contributes to this endeavour by exploring the ways in which moving by walking becomes especially relevant at projected activity closings, and may be mobilized to accomplish the end of talk at a particular place and begin the activity of moving on together. Throughout our analyses, we will deal with how embodied talk-in-interaction progresses incrementally and is literally organized step-by-step. Participants' footing practices are thus not taken metaphorically, in contrast with Goffman's (1981:124) famous use of the term, but studied as an embodied phenomenon to show how these can be constitutive of activity closings.

\section{The data}

This paper is based on video recordings of different settings and activities. The recorded events have in common the fact that participants are involved in shared walking with interspersed periods of stopping, where some participants show or explain details of the physical surroundings to others. These guided visits all share a spatial organization based on the alternation between static and mobile moments, between stopping and walking towards the next place (cf. Birkner and Stukenbrock, 2010; Broth and Lundström, 2013; De Stefani, 2010; vom Lehn, 2013; Pitsch, 2012).

In the corpora used, different languages are spoken: Swedish, French, and English. The Swedish data feature, on the one hand, an introductory tour at a boat club, where a club official explains how things work to a prospective member (corpus Pier), and on the other hand, walks undertaken as part of energy auditing, involving energy auditors and local representatives at two small enterprises in northern Sweden (corpus Energy Analysis). The French data were collected during three visits: an architectural guided tour of a campus, in which the guide walks through various buildings with three co-participants (corpus Archivis); a historical guided tour of the city of Lyon, with a larger group of participants (corpus Tourly); and a guided tour in an old garrison by a local activist leading a group of citizens involved in a participatory urban project aiming at the transformation of the garrison into a public park (corpus Blandan). English is spoken in a recording of a tour offered by a French cook to a small group of American and Australian guests in a market street in Paris, as an introduction to a gastronomic class (corpus Cooking).

Our analysis focuses on the relevance of walking at particular sequential positions, in which a conversational activity is being brought to a close (section 5). We begin by studying cases in which the participants engage in very smooth and finely coordinated collective walking (section 6) and then show cases where starting to walk is clearly more of a negotiated accomplishment, and where people may begin to walk at different times and temporarily halt their projected departure (sections 7 and 8). To further demonstrate the participants' normative orientations towards walking as projected at closings, we finally also turn to one case where walking is treated as observably absent and another case 
where a participant's apparently un-coordinated walking away is openly sanctioned by one of the co-participants (section 9).

5. The phenomenon

The phenomenon of interest is observable in the following brief excerpts (1--3):

(1) Pier [17.37:11--17.37:27]

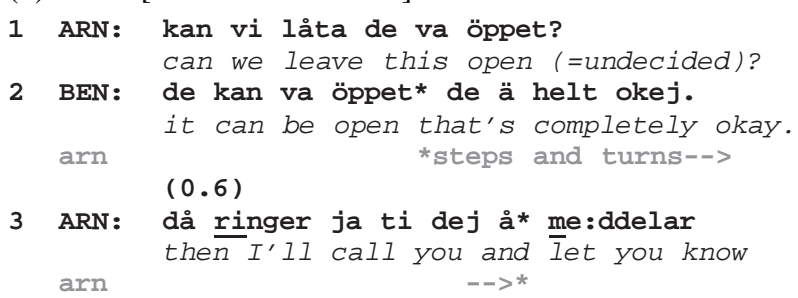

(2) Tourly (tourly2 [39.50])

01 GUI: voilà, pour euh: petite parenthèse autour de cha*llier. gui. that's it, for ehm: (a) small parenthesis about Challier.

(3) Blandan (casbla-vis-251008-vis3-gui1 [10.08])

01 GUI: donc* là, on commence à avoir un aperçu du château, entre so the $\overline{r e}$, we begin to have a glimpse of the castle, between gui *points-->

$02 \quad(0.9)$

3 GUI: entre $1^{\prime}$ château et ici:, y a: un: gro: $s^{\wedge} e s p a c e$ de végétation

4 between the castle and here, there is a big green space

4 euh (0.4) enfin important du site quoi.*

ehm (०.4) well important within the site right.

$05 \quad(0.5)$

6 GUI: ${ }^{\circ}$ un des: ${ }^{\circ}(0.9)$ un des plus importants, >y en a deux, <

${ }^{\circ}$ one of ${ }^{\circ}(\odot .9)$ one of the most important, >there're two of these<

7 ANN: ${ }^{\circ}$ elle est belle, ${ }^{\circ}$

it's beautiful, 。

8 GUI: ${ }^{\circ}$ qui sont vraiment euh ${ }^{\circ}$

${ }^{\circ}$ which are really $\mathrm{ehm}^{\circ}$

9 ANN: ${ }^{\circ}$ comme ça:, ${ }^{\circ}$

- like that, ${ }^{\circ}$

10 GUI: ${ }^{\circ}$ de grands *

$\circ$ of big ( $\left.{ }^{\circ}\right)^{\circ}$

*walks away-->

In all these cases, we observe that a participant initiates a movement projecting walking away at closings of a sequence or an activity. In excerpt (1), the movement is initiated by the guiding person, a boat club manager (Arne), after the completion of an adjacency pair by a prospective member of the club (Benny). The guide initiates a turning step that projects walking upon receiving an answer to his query. The step and turning movement is continued into what might be considered the upshot of the adjacency pair. In excerpt (2), the guide explicitly concludes his comment with "'voilà', further expanded by a formulation (Garfinkel and Sacks, 1970) of both the topic ("Challier', the name of the historical figure he was talking about) and the activity (a parenthesis). On the last syllables of his turn, he begins to walk away, thus reflexively achieving the closing and its accountability. In excerpt (3), the comment of the guide, introduced by a conclusive "donc"' (1) is progressively brought to completion, first with "quoi"' (4) and a retraction of the pointing gesture, second by subsequent additions, produced with a lower voice as delayed completions intertwined with the conclusive assessment of a participant, Anne (7, 9). Finally, the completion is made accountable by the guide walking away on the last, almost inaudible syllables of her incrementally extended turn (10). In these three cases, the completion of turns and sequences is accountably produced by a participant orienting to and mobilizing a range of resources -- such as syntax, prosody, gesture, and starting to walk away.

In the remainder of the paper, we focus on walking at closings as an interactionally achieved and negotiated practice. As such, it does not only concern the speaker but all co-participants, who collaborate in responding to or even initiating completion. 


\section{Smooth departure at sequence closing}

We start our analysis with the simplest configuration (which is not the most frequent, for reasons that will be clear in later sections): at the closing of a sequence, which coincides with the closing of a 'big package' (Sacks, 1992/II:345), like a story telling, an explanation or a topic, the participants walk away together. These straightforward and often very smooth cases show that the end of the sequence and the beginning of the walking is a thoroughly coordinated achievement, and that walking away is a concerted action which not merely accompanies closings but also achieves them.

In excerpt (4), Conny is finishing a story about a motorcyclist who had an accident with a hawk. The hawk hit the cap the rider was wearing when he was driving at a fairly high speed. The motorcyclist made it, but not the bird. As a memory of the accident, the motorcyclist saved his hat and had the bird stuffed. The story ends as we join the excerpt:

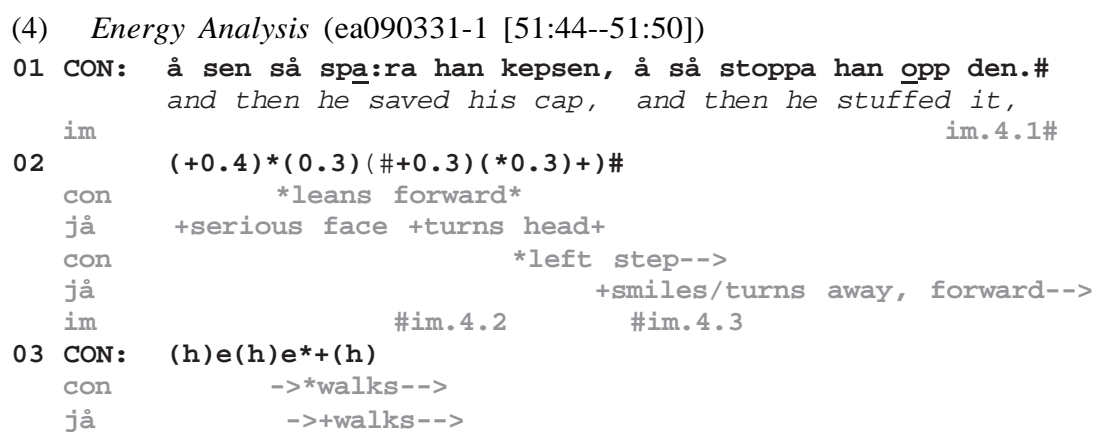

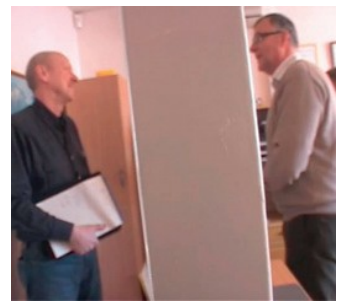

im. 4.1

$\operatorname{im} .4 .2$

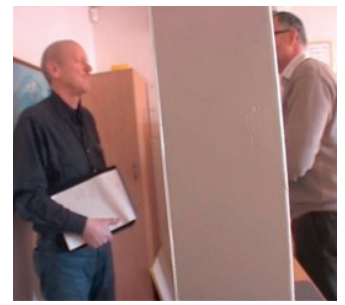

04 CON: (0.6) \#hai (0.4) a [de myck]e.

$(0.6)$ alright $(0.4)$ yes[it's a lot.

im

$05 \mathrm{JA}:$ $[\mathrm{a}:: a ̊::$,

[yeah]

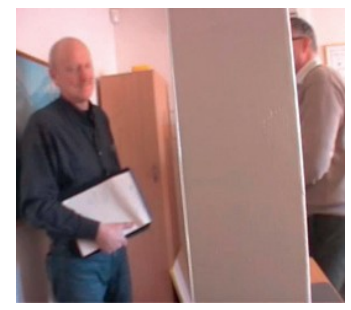

im. 4.3

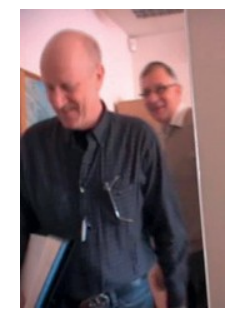

im. 4.4

Syntactically and pragmatically complete, and with falling prosody on the last syllable, the end of line 1 offers all the characteristic features of a completed TCU (Ford et al., 1996). At this point, the only thing missing for the story telling sequence to be closed is the story uptake (Jefferson, 1978), which is interactionally produced in the next line.

Conny's turn is immediately responded to by a facial change from a smile to a more serious face by Jan-Åke, possibly registering its unusual character. After a brief moment in which the two participants stand looking at each other, Conny, the story-teller, leans slightly forward (Image 4.2). Very shortly thereafter, Jan-Åke produces a distinctive head turn (Image 4.3--4.5), which seems to do two things at the same time: first, it responds to the story, with a kind of "sympathetic sigh"; second, it recognizes and aligns with Conny's invitation to move on. This understanding is also demonstrated by Conny's embodied response to Jan-Åke's head turn: he now begins to take a first step forward and soon also laughs in return (3). After that, Jan-Åke transforms his turning movement into a walking one.

In sum, excerpt (4) shows the closing of a story telling sequence. Beginning to move away features in the pursuit (by Conny), production (by Jan-Åke) and recognition (by Conny) of a response to the story. As such, moving away is an integral part of the closing of this storytelling sequence, and is achieved in an embodied way by the participants leaning forwards and turning together towards the office door.

In the next fragment (5), the participants' bodily reorientation for walking away is done in the same sequential position, at sequence closing, but in a more complex concerted bodily configuration. The fragment comes from an architectural visit. Jean, the guide, is explaining that some people have interpreted the balustrade above the entrance hall, where the participants are standing, as being similar to a balcony above a ballroom: 
(5) Archivis (salle de bal [moy1/47.35])

01 JEA: et ils évoquent ça, ${ }^{*}$ comme une salle de bal

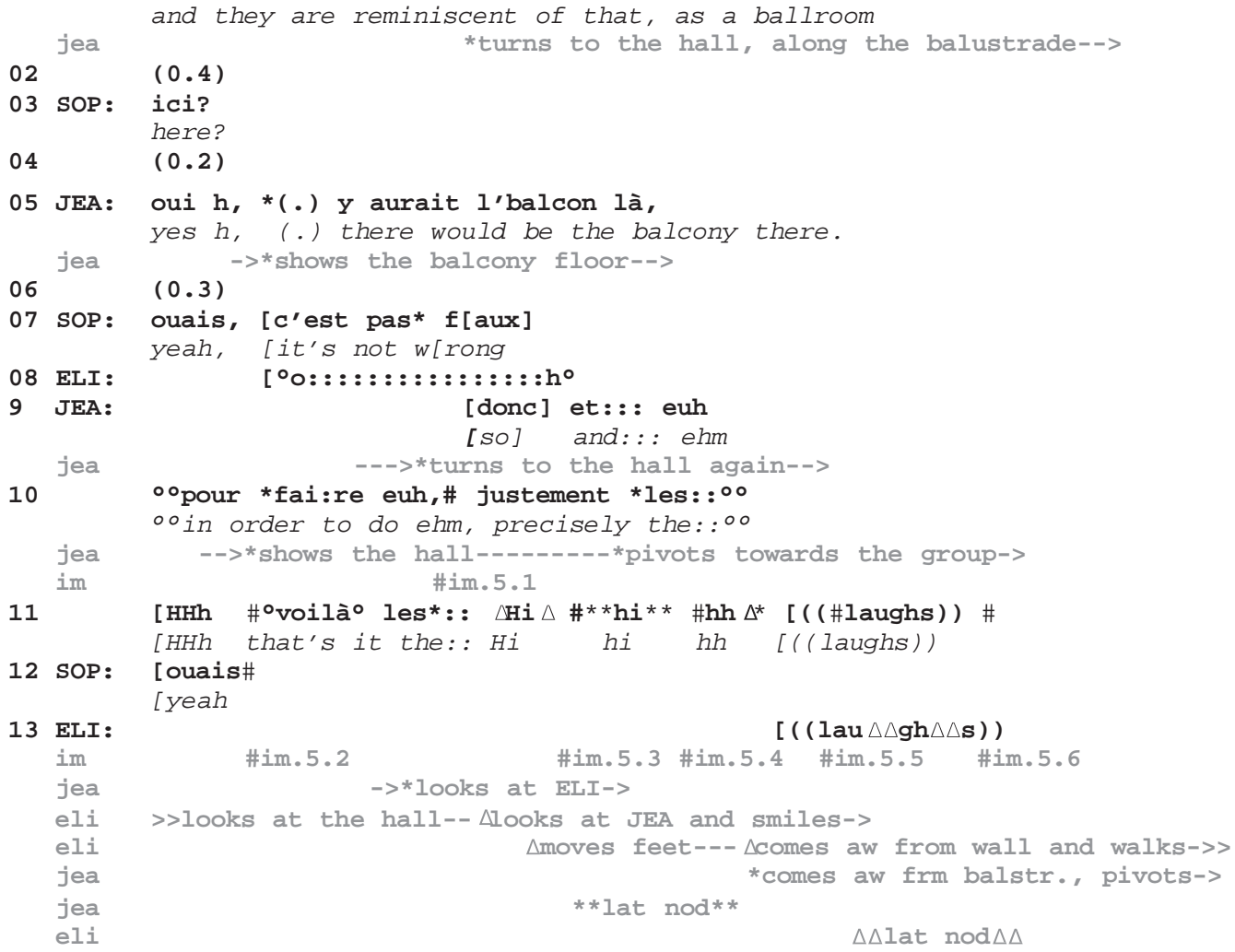

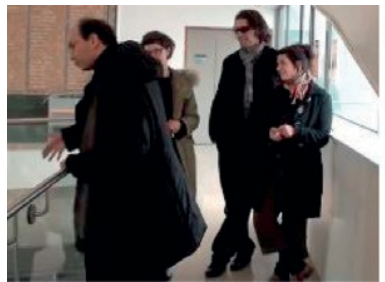

im. 5.1

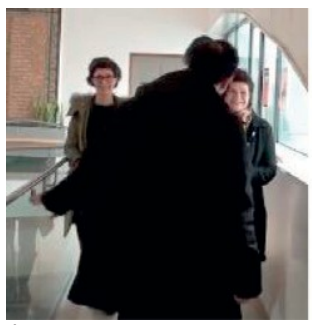

im. 5.5

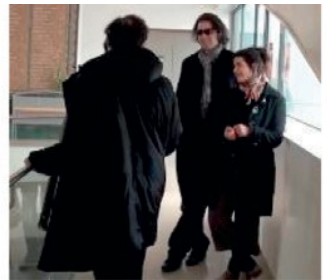

$\operatorname{im} .5 .2$

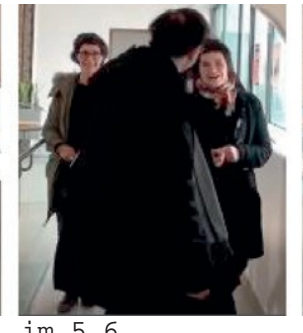

im. 5.6

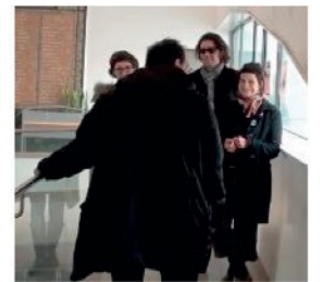

im. 5.3

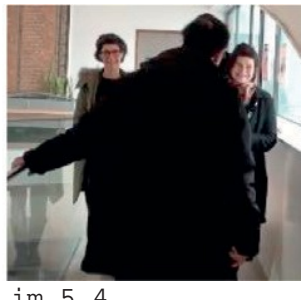

im. 5.4

14

\#(1‡+.*1) \#

\#im.5.7 \#im.5.8

-->*Walks and looks forward, besides ELI-->>

łwalks-->>

sop

yan

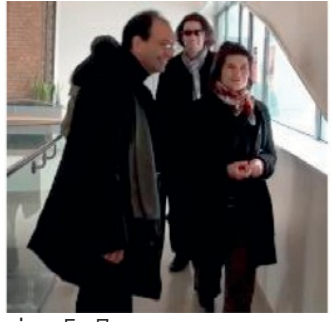

im. 5.7

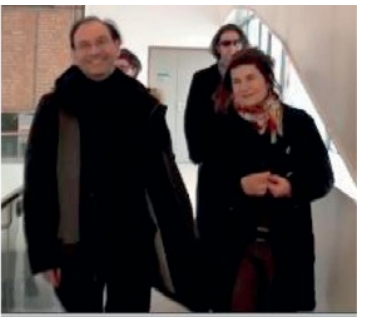

im. 5.8 
Jean's description (1) is not immediately grasped by the co-participants; after a delay, Sophie initiates a repair (3), prompting a new description (5) which is also embodied by Jean turning towards the hall, leaning on the balustrade and showing the space below. This explanation is received by a positive acknowledgement and an assessment by Sophie (7) and by a lengthened change-of-state token by Elise (8).

At that point, Jean expands it further, with “donc” (9), showing the hall again (Image 5.1) and alluding in a syntactically unfinished utterance (10--11) to what activities could be done on the balcony. The completion of his turn is achieved by bubbling laughter (11), joined by Elise (13).

During laughter, Jean gradually turns away from the balustrade (Image 5.2) towards the group. He looks at Elise, who looks back at him (Image 5.3), smiling, and visibly addressing her as the main recipient. Mutual gaze and joint laughter display the alignment of these two participants -- as well as the repetition made by Elise of the lateral nod that Jean produces when leaving his utterance unfinished. Their bodies align too, in a finely coordinated manner: Jean performs a gradual pivoting away from the balustrade, turning towards the group and then orienting forward. His movement forwards is circular and progressive, permitting him to gaze at the co-participants, while he keeps his hand and stretched arm on the balustrade (Image 5.4). His body moves forwards when his hand finally lets go of the balustrade (Image 5.5). At that exact moment, Elise, who was leaning against the wall, changes the position of her foot, redistributing her body weight from her left to her right foot: she leaves the wall (Image 5.5) and begins to walk. Jean pivots forwards (Image 5.6), slowly, coordinating with Elise moving forwards (Image 5.7): as she reaches him, they walk together side by side (Image 5.8). From their position at the back and as secondary recipients of Jean's action (mainly directed towards Elise), Sophie and Yan follow this emerging movement.

The accountability of Jean's turn completion is thus achieved by him with a lower voice, laughter and by him moving away from the balustrade, turning towards the group and initiating walking forwards in the trajectory of the guided walk. This completion is also interactively achieved by Elise, who laughs with him, does the same head movement, and begins to move away from the wall at the very moment Jean's arm leaves the balustrade: both reorganize their body weight within their mutually adjusted forward-looking trajectory and coordinate their joint walking away.

To sum up, in excerpts 4 and 5, walking away is strongly coordinated, being the fruit of mutual alignment and emerging reciprocal adjustments: this shows that it is a concerted and methodic interactional practice. The very fact that walking away is initiated and achieved over time, within a projectable trajectory, and designed in a particularly visible and emergent way by the participants, highlights the sequential feature of this movement. Walking away strongly orients to the completion of the turn and the sequence, is initiated within the pre-completion space and achieved immediately after completion. In turn, and reflexively, it contributes to this completion and to its accountability for all participants.

\section{Step-wise walking away}

Most of the time, walking away is characterized by several negotiations organizing the transition from one activity to another. In this section, we show some delaying practices mobilized by the participants and the social actions these practices make possible within Step-wise walking away the ongoing closings.

Contrary to the examples above, in which the participants were all moving together, participants may also take steps in more dispersed ways. In the next case (7), Mats, the owner of a store, is telling Conny, the expert-in-chief of a group of energy auditors, about how little he had to pay for one of the greenhouses that make up his store. At this moment, Lars and Richard are more peripheral participants, not being gazed at by the two main interlocutors (cf. Sophie and Yan in excerpt (5) above):

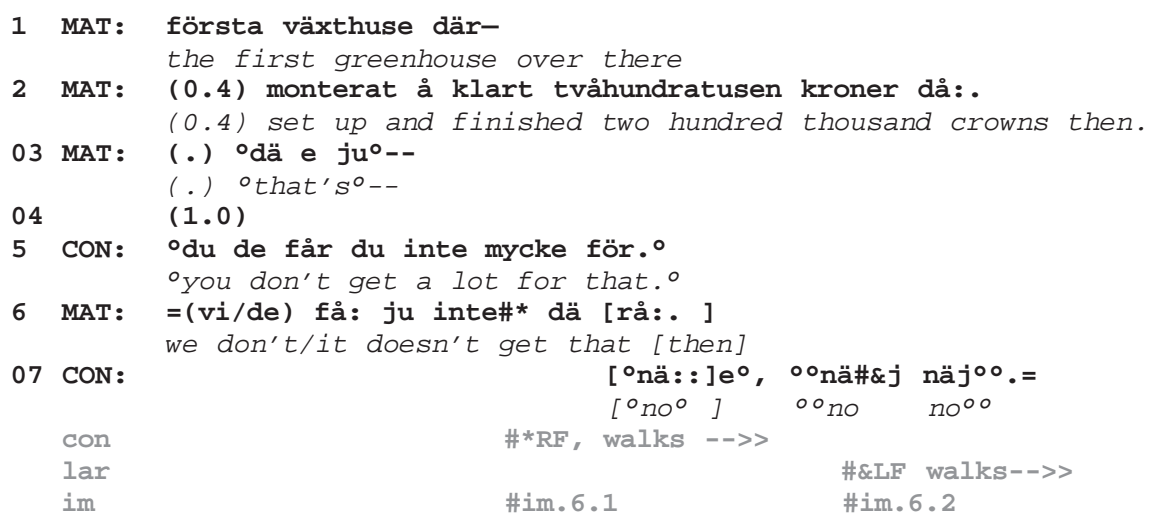




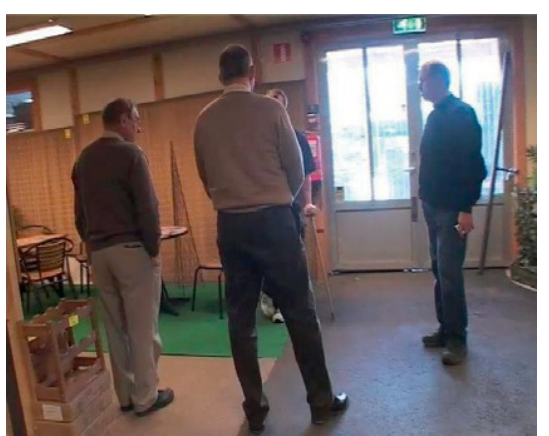

im. 6.1

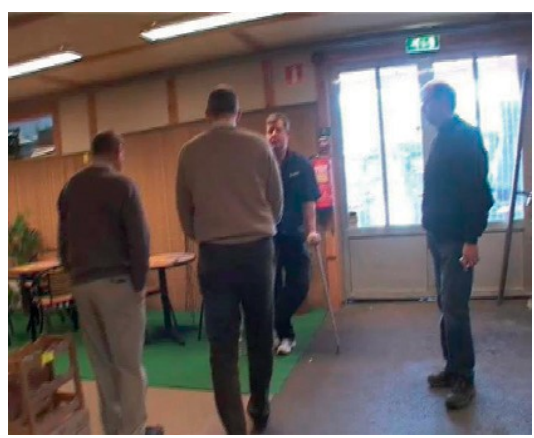

im. 6.2

8 MAT: =>de ä där\#*för dom ha- vi< ha byggt mycke \#vä*x§@thus, $>$ that's why they've- we< 've built a lot of greenhouses, con $\quad * . . . . .$. gazes at Mats-...-.-.-.*, r, mat SRF down, walks-> ric im

\#im.6.3 \#im.6.4 $@$ LF, walks->>

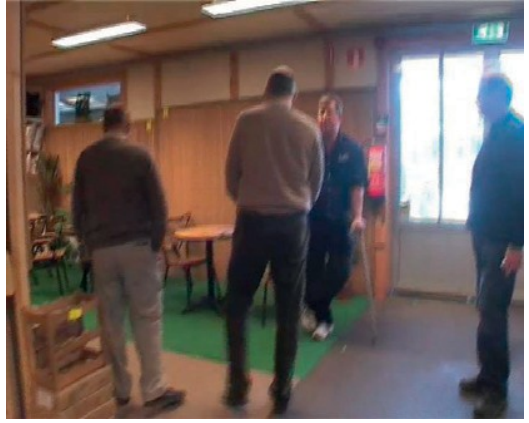

im. 6.3

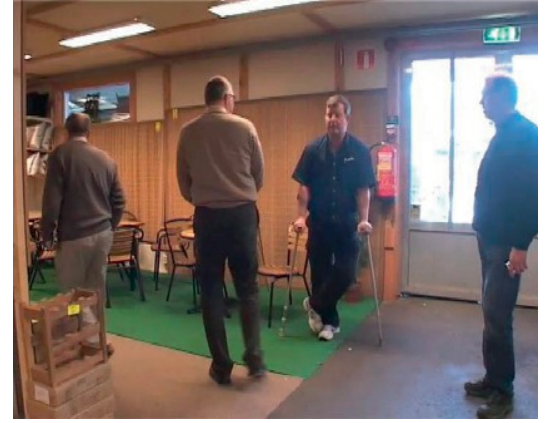

im. 6.4

9 MAT: (.) \#o:ch för miljöns skull då.\#

(.) and for the sake of the environment then. im \#im.6.5 \#im.6.6

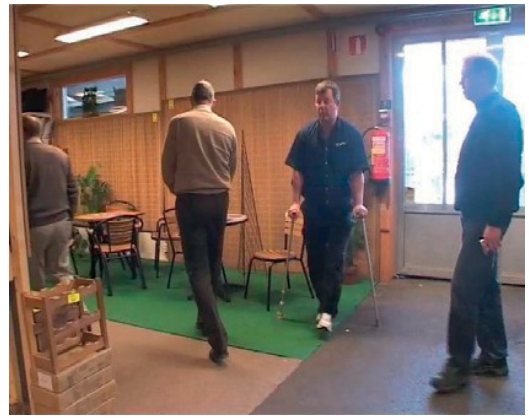

im. 6.5

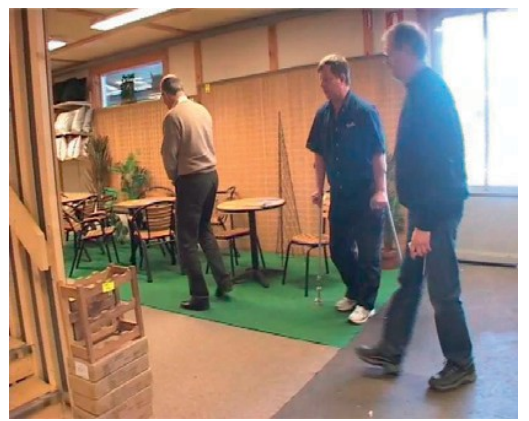

im. 6.6

10 con: (0.2) ja de e klart.

After announcing the actual sum (two hundred thousand Swedish crowns) in a turn that is designed so as to present this piece of news in turn-final position (2), Mats begins a new utterance that is however never brought to completion (3). Instead, there is a full second's pause (4), before Conny reacts to the stated amount as a small sum (4). This understanding is confirmed by Mats and further agreed upon by Conny (7) -- who has then just started to walk away -

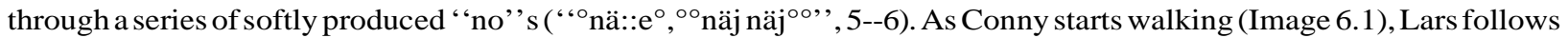
him (Image 6.2), but Mats and Richard do not yet move. Instead, Mats takes a new turn that is referentially dependent on the previous shared understanding, explaining that the low cost is the reason why they have chosen this solution (7). This 
expansion is acknowledged by Conny who redirects his gaze towards him as he passes (8, Images 6.3, 6.4). As Mats (who is using crutches) and Richard themselves finally start walking (Images 6.5--6.6), Mats also gives an additional reason for building greenhouses (8). Conny agrees with this as something self-evident (9).

This excerpt shows how different participants start walking at different structural locations in the organization of the ongoing talk. Conny is the first to start moving, at a point where a mutual agreement regarding an assessable (" that two hundred thousand crowns is not a big sum of money for building houses'”) is evident and where the completion of Mats' turn is projectable, although not yet complete (6). Being a second pair part to Conny’s immediately preceding question/ request for confirmation, Mats' turn also completes and closes an adjacency pair. As Conny starts to walk slightly before he begins his next turn (the series of “nos", line 7), this turn is produced as he is already moving, and is thus accountably post-final. Lars starts walking shortly after Conny, and may thus be understood to be just following him. The second main speaker in the current sequence, Mats, starts walking significantly later, at a subsequent TRP that emerges as his added explanation is only one syllable away from syntactic completion. This syntactic point is also oriented to by Richard, who starts walking almost exactly at the same time (8).

As participants start walking, both topical and sequential aspects of the unfolding talk-in-interaction turn out to be relevant. If walking indeed embodies an endogenous analysis of the ongoing talk, there is also evidence that it reflexively configures talk and is used to project and achieve sequence closing. Walking is initiated before turn unit completion of both other (Conny in line 6 and Richard in line 8) and self (Mats in line 8), and thus brings a new kind of time constraint to bear on the remaining talk. If someone aims to add talk to the current sequence at this location (Broth and Lundström, 2013), the window of opportunity for this is about to close. This embodied time constraint is observable in Mats' relatively quick delivery of the beginning of his expansion, slowed down only as he again receives Conny's gaze (8). It can be noted that although Mats' expansion brings him Conny’s gaze, it doesn’t gain it for very long nor does it stop Conny’s walking away. This possibility may in fact be oriented to by Mats who continues his turn by an increment initiated by the conjunction "och", ("and") that allows it to be quickly re-completed. What is said as the participants have started to move is therefore heard and produced in a particular way, as part of a sequence that is about to end.

8. Walking away intermittently: taking a step away, stopping, and going

The last excerpt has shown that within a sequence closing there are various positions at which walking can be initiated, which can be exploited or not by the participants, all together or one after the other. Whereas in the excerpts discussed so far movement was progressively achieved in a continuous manner, in the case discussed below the movement is initiated, suspended, and then resumed. We particularly focus on the sequential environment in which these suspensions are achieved and in their reflexive impact on the sequential organization of turns at talk.

In excerpt 7, divided into three separate fragments (7a--7c) for the sake of analysis, Jean gives some details about a theatre the architect chose to lodge below an amphitheatre -- the latter occupying the upper floor where the group is standing. Some architectural constraints result from this particular embedded structure, which are revealed by Jean.
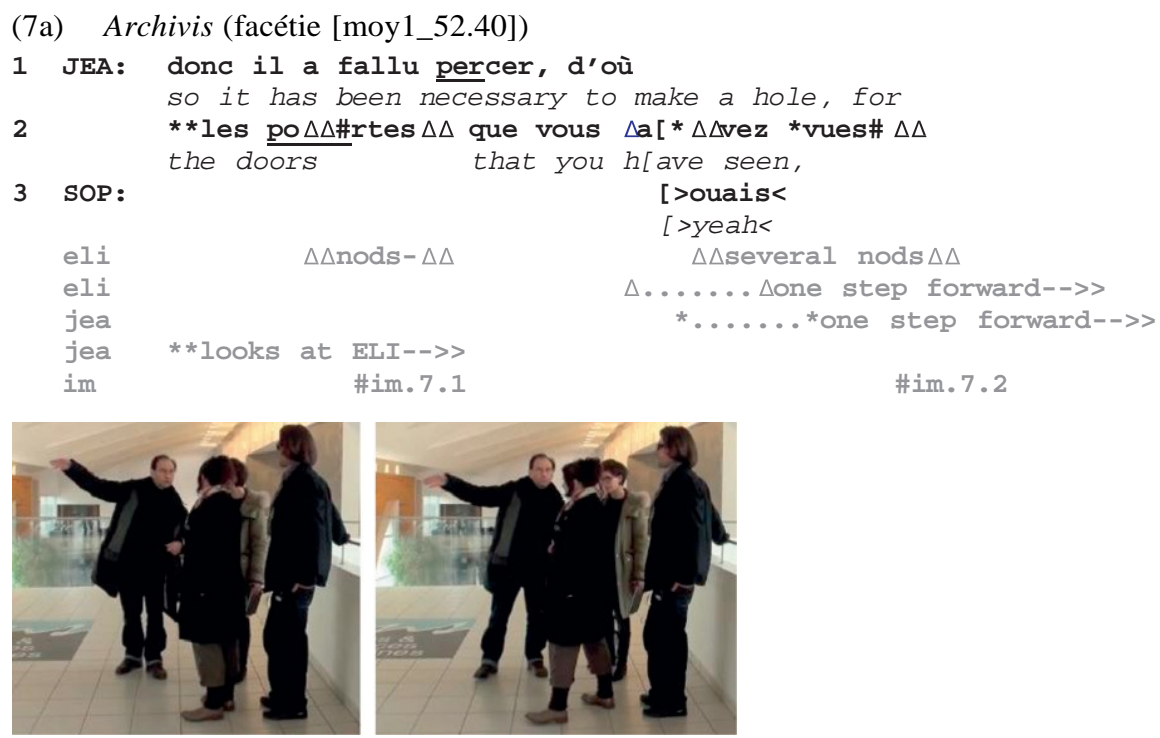

$\operatorname{im} .7 .1$

im. 7.2 
Jean ends his explanation about the difficulties encountered by the first time users of the theatre, not having doors big enough for the stage scenery and props to fit through. As a consequence holes had to be made for new doors, that were not originally planned by the architect. This last piece of information is received by Sophie with a brief acknowledgement (3) and by Elise with a series of nods (3).

Just after Jean's mention of the doors, Elise begins to move, taking a step forward. Her step forward, in this environment where various reception tokens have been produced, displays not only her understanding, but also her treatment of what has been said as possibly complete. By beginning to move, she embodies her interpretation of the possible sequence closings. Jean begins to move immediately after her, perfectly adjusting his step forward with her step (Image 7.2). At this point, he orients to her movement and aligns with her.

What follows is a pause (4), constituting a slot where the sequence could be definitively treated as closed and the group move away. But the other two participants do not move:

(7b) Archivis (facétie [moy1_52.40])
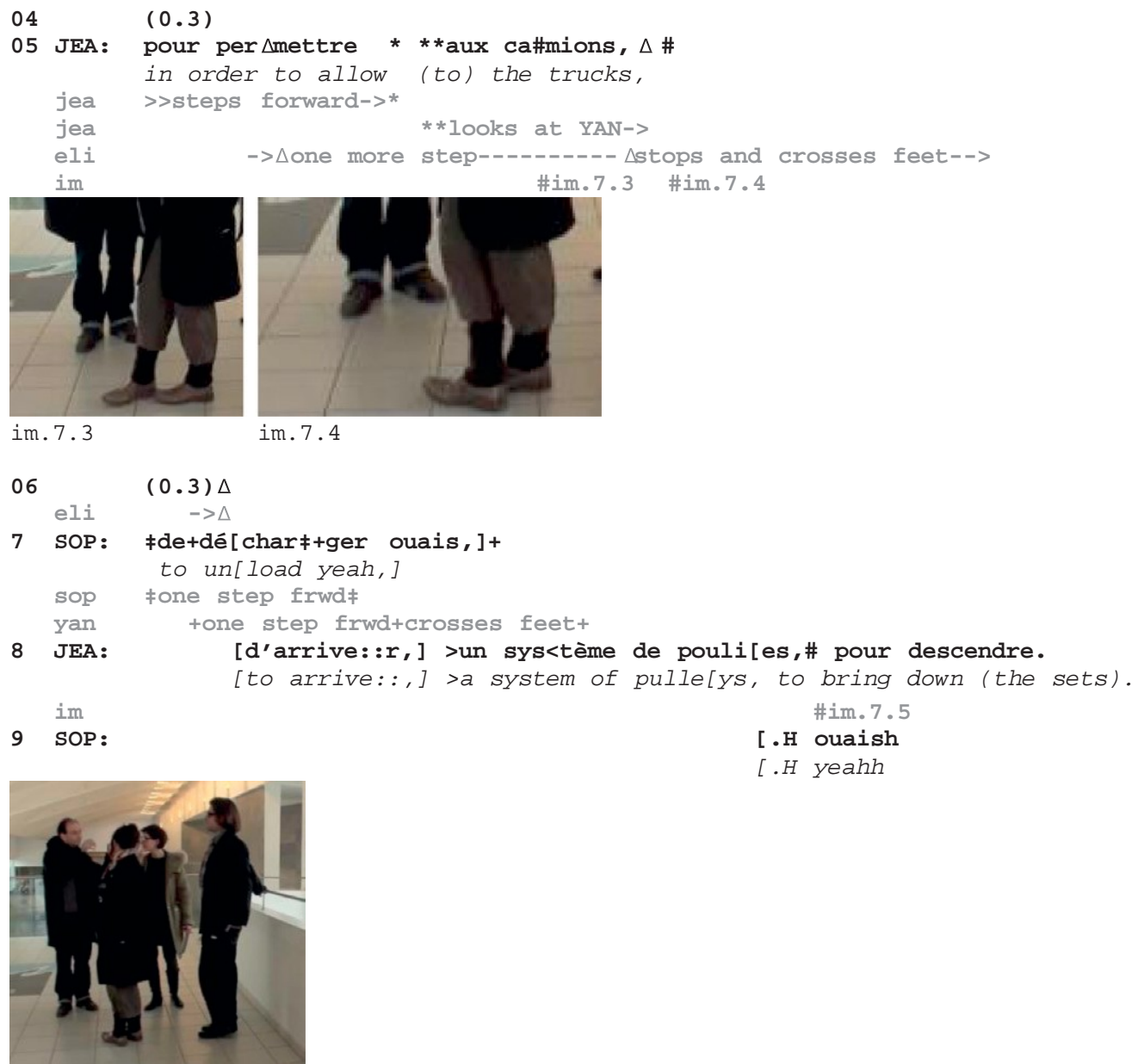

im. 7.5

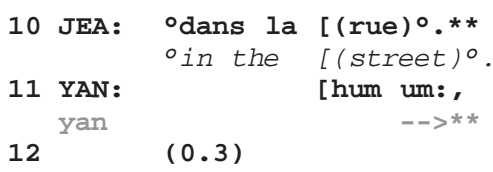

The growing pause ends as Jean produces an increment (5) to his previous turn (2) (Ford et al., 2002): he adds a dependent infinite clause introduced by a preposition. As he utters the verb (" permettre', 5), he stops walking and again takes up a position with his two feet firmly anchored on the ground -- assuming a stable posture. Moreover, whereas he 
was looking at Elise during his previous turn, he now turns to Yan, who continues to listen while standing still. As regards Elise, she takes one more step (Image 7.3), but after the argument of the verb in Jean's turn, she stops and crosses her feet (Image 7.4). Her posture is less stable than Jean's or Yan's, and can be considered the embodied product of an orientation towards an emergent and projected movement that was nevertheless subsequently repaired into a standing position.

At that point, Jean's utterance is still unfinished and projects more to come. After a short pause (6), the main verb is proposed in a collaborative completion by Sophie (7), and is, almost at the same time, completed by Jean too (8), but with a longer construction. During this collaborative completion, Sophie moves one foot forward, without actually taking a step, and Yan does the same. The participants are still engaged in the current face-to-face F-formation (Kendon, 1990) at that point (Image 7.5). They produce response tokens to Jean's description $(9,11)$ but they do not yet move away.

Maybe taking advantage of this F-formation still in place, Jean now introduces a new anecdote ("autre facétie”, 13) about the architect:

(7c) Archivis (facétie [moy1_52.40])

13 JEA: autre: facétie qu'i m'a fait, c'est qu'il a pas [fait

another joke he made to me, it's that he hasn't [made any

14 ELI:

15 JEA: d'rideau coupe *feu.*

[( (small laughter $))$

fire curtains.

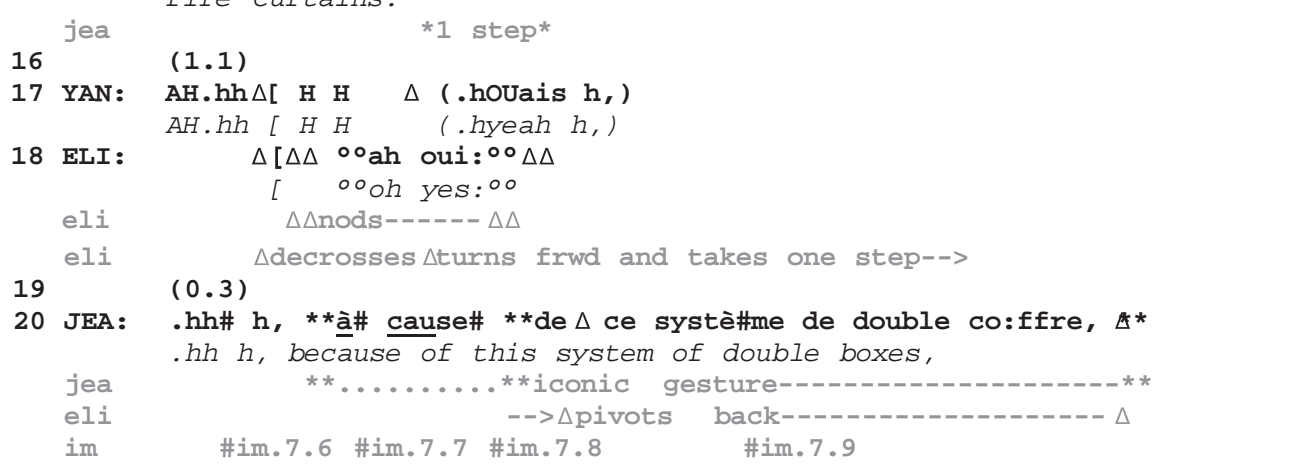

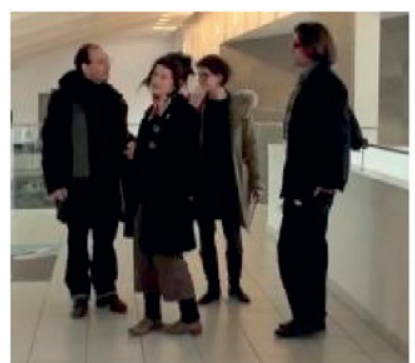

im. 7.6

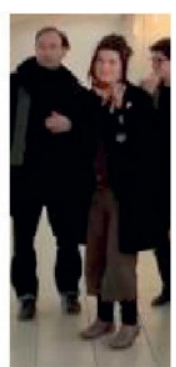

$\operatorname{im} .7 .7$

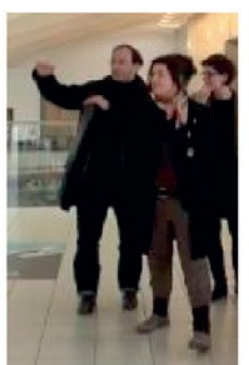

im. 7.8

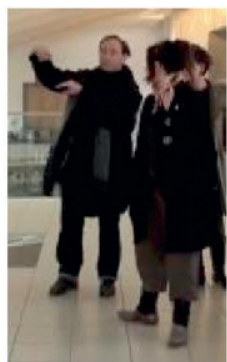

$\operatorname{im} .7 .9$

(0.2) là où on met le (

22 SOP:

(०.2) where we put the (

$\left[\begin{array}{ll}{[} & \text { ) }] \\ \mathrm{mhm} & ]\end{array}\right]$

33 JEA:

donc [ses assistants $\left[{ }^{*} n^{\prime} \text { ont pa:s, }>^{\circ} \text { voilà }{ }^{\circ}<(.)\right]^{*}$ donc il a fallu

so [the assistants [didn't, $>^{\circ}$ that's it $\left.{ }^{\circ}<().\right]$ so it was necessary

24 ELI :

[ouais (.) ${ }^{\circ}$ des choses qu' (auraient pu) ()$\left.^{\circ}\right]$

[yeah (.) ${ }^{\circ}$ things that (could have been) ( $\left.)^{\circ}\right]$

25 JEA: que moi $\Delta$ je łdégage\# deux rangées de +fau $\Delta$ teuil*s. \#

that $I$ make free two rows of seats.

eli

sop

yan

jea

im

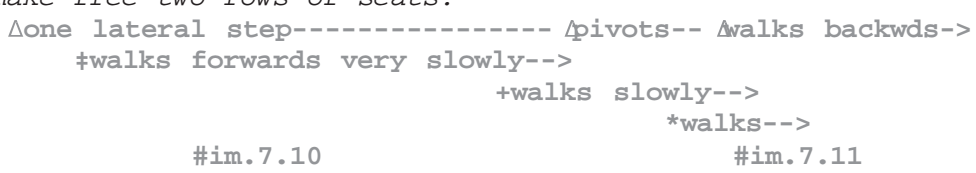




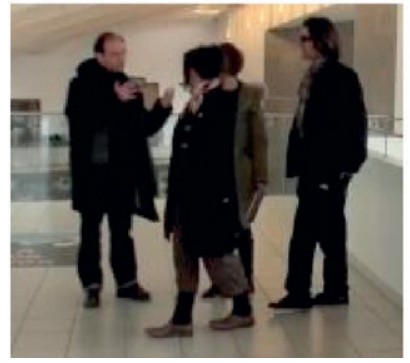

im. 7.10

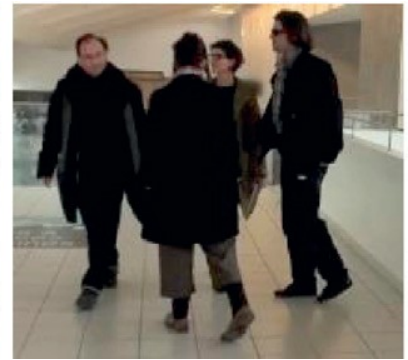

im. 7.11

$26 \quad(0.7)$

27 YAN: résoudre le: les difficultés [là.

28 ELI :

(in order to) solve the: the problems [there.

[c'est chouette sun ( ).

[it's nice a ( $)$.

$29 \quad(0.7)$

30 YAN : ah ha hh

$31 \quad(1.0)$

Adding an anecdote about the architect, Jean mentions a new detail, the absence of fire curtains (13--15): in precompletion position, he takes a step forward (15). The mention of this problem is received, after a pause (16), as news by Yan, who also laughs (17), and by Elise (18), visibly nodding. At that point, Elise ceases to cross her legs and turns forwards, taking one step away. This movement displays again both her understanding of the story and her treatment of Jean's turn as complete.

Again, after a small gap (19), Jean produces an increment, thus expanding his previous turn and transforming it from a complete to an incomplete (or yet-to-be-completed) one. This increment is oriented to by Elise as a re-completion and it occasions a stop in her trajectory: having already begun to walk away (Images 7.6, 7.7), she stops, pivots, and orients back towards the group (Images $7.8,7.9$ ). The redirection of her trajectory shows that her walk is indeed finely tuned to the emergent sequential organization of Jean's talk.

As regards Jean, he goes on with a series of iconic gestures - attracting the attention of the recipients -- and further expands his explanation $(21,23,25)$. This explanation is continuedby “donc', possibly projecting an imminent completion (23), introducing a consequence that is overlapped by Elise, who produces a conclusion too (24), and that is left unfinished by Jean who completes it with the particle “voilà', (“'that's it”' 23). During this overlapped segment, Jean takes a step forward, confirming the ongoing completion.

He nevertheless adds another "donc"' (at the end of line 23), introducing the end of the story (25). During this last addition, all the participants begin to walk: Elise takes a lateral step (Image 7.11), as Sophie also begins to move very slowly, followed by Yan. Elise walks backwards (Image 7.12) for a while -- and this double bodily orientation back to the group and forwards in the projected trajectory of the joint walking displays her availability for new possible increments. In this case, Jean is the last participant to walk, in a pre-completion position, just at the end of his turn. So, when his sequence closing turn is finally brought to completion, all participants are walking together (Image 7.11).

The episode presented in excerpts 7a--7c offers various instances of the same phenomenon: a sequence is possibly brought to completion, some participants orient to it and begin to walk, but immediately stop as an increment is produced, expanding and postponing the actual completion. Going and stopping, then going again, are movements that exhibit the finely tuned responsiveness of the participants to the incremental organization of talk, which reflexively adjusts and responds to the incipient and ongoing walking of the participants.

\section{Normative orientations to unexpected behaviour: missing and misplaced walking}

The previous excerpts show that walking away is a collective achievement. Even when it is initiated by one participant, the others align with this action. When some participants do not align, turns at talk as well as walking are delayed and adjusted accordingly. These phenomena show that participants are responsive to such incipient movements: their embodied responsiveness constitutes a 'next-action proof procedure' displaying the relevance, for them, of walking away as a concerted practice.

This responsiveness also demonstrates participants' normative expectations towards walking away. Two particular environments exhibit these normative orientations in a particularly vivid way. First, the fact that participants orient to 
walking away as a relevant, projected, expected action becomes visible as they treat the absence of walking away as noticeable and as they exploit different practices to mobilize a response (extract 8). Second, the fact that participants orient to walking as expected at specific sequential moments becomes visible as they treat walking away at other moments as misplaced; similarly, the fact that participants orient to walking as a collective concerted achievement is visible as they treat unilateral walking away as problematic (extract 9).

Extract 8 is taken from a gastronomic tour. A few minutes earlier, Monique, the guide, has insisted on the difference between a "boulangerie" and a "pâtisserie", i.e. between shops specialized in bread vs. pastries - although some less sophisticated bakeries do both. This is the case of the place commented on in the excerpt, as the group stops in front of a "boulangerie”, which does pastries as well.

(8) Cooking [moy4_19.08--19.24]

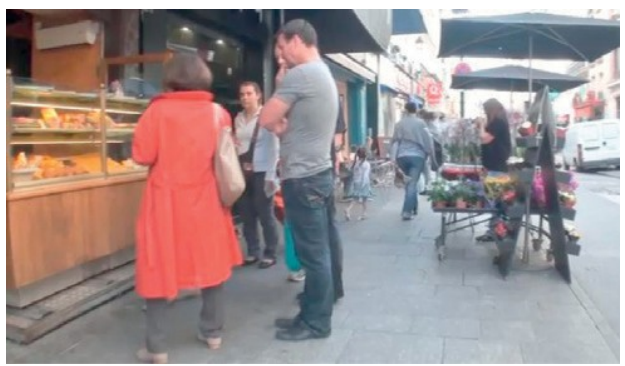

im. 8.1

MON: so this is a boulanger. em (0.3) he does, (0.4) pastries, (0.3) you'll see they look very good to you:, and they're

\#not bad, $(0.5)$ but they're *not (.) the level* that $I: *:$, \# mon

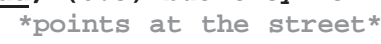

05 MON: voilà.

that's it.

06

$(0.3)+£(1 \$ \% .4) \#$

+ walks $->>$

£walks - >>

\$walks->>

\%walks->>

\#im.8.3

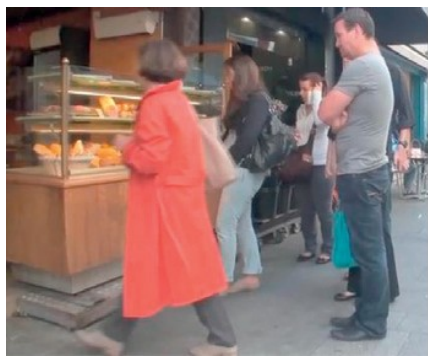

im. 8. 2

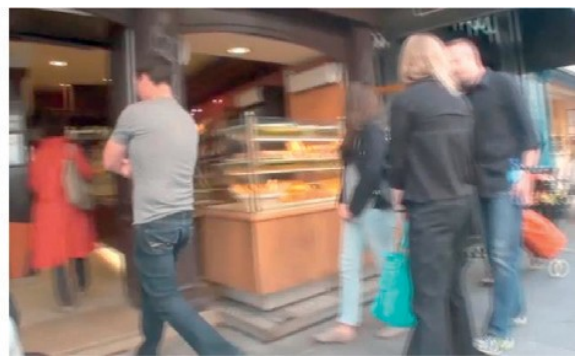

im. 8.3

Monique's explanation is left syntactically unfinished (3), but is made intelligible by a gesture pointing to the " "pâtisserie"' they have visited earlier, providing for the predicate introduced by the relative construction "'that I:", and by the very fact that she begins to move and enter the shop (Image 8.2). In this sense, her walking displays that, for her, the turn and the sequence are brought to completion: actually, walking away brings the turn to completion.

But here the completion is followed by a longer pause (4) during which the co-participants stand in front of the shop and do not yet move. Monique orients to this absence of walking: with falling intonation, she adds "voilà." (5), a French particle typically used in turn or sequence final position to express closure. In this way she accountably confirms the previous completion. As soon as "voilà"' is uttered, all the members of the group enter the shop, in a compact and concerted way. 
So, in this excerpt, the person achieving closing and initiating walking orients towards the absence of her co-participants' beginning to walk by re-doing the closing verbally (using the terminal particle " voilà'). This offers again a sequential point at which the co-participants might align with walking away, consequently mobilizing their embodied response.

A second case showing participant orientation to unexpected behaviour involves one participant walking away unilaterally, without coordinating his departure with anybody else. On top of this, he walks away as another participant is still delivering news directly to him, i.e. in the middle of a turn of which he is the primary addressee. This departure is noticed by the co-participants as strange:

(9) Energy Analysis (ea090401-2 [17:24--17:35])

1 RIC: de e ingen va heter 're=

there's no what do you call it=

2 RIC: =lagt nån markisolering under asfalten eller [ nå.

03 LAR:

=put any ground insulation under the asphalt or [anything

4 LAR: (0.5) de va en ${ }^{\circ} \mathrm{mk}-{ }^{\circ}$ stor plan bara här=

[no

(๑.5) there was just $a^{\circ} \mathrm{mk}^{\circ}$ - big field here=

(०.5) there was just a big field here=

5 LAR: =me en massa blomme\#* $r$ ti+di++ga[re]

=with a lot of flowers earli[er

6 RIC:

07 MAT :

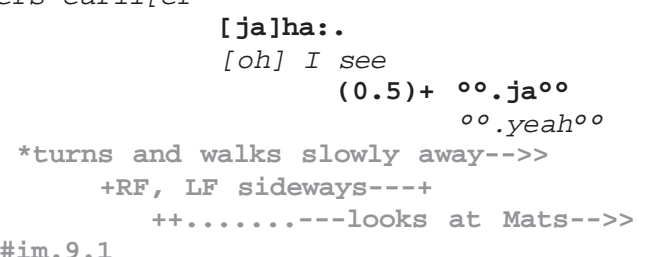

lar

lar

im

\#im.9.1

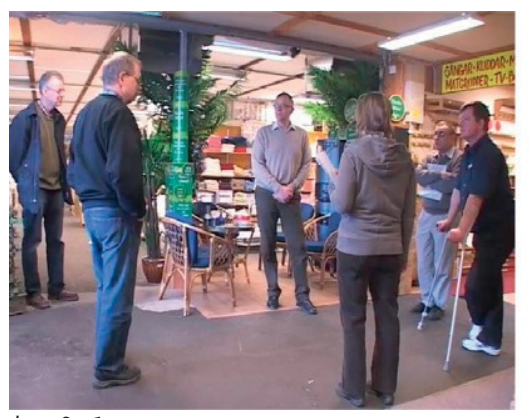

im. 9.1

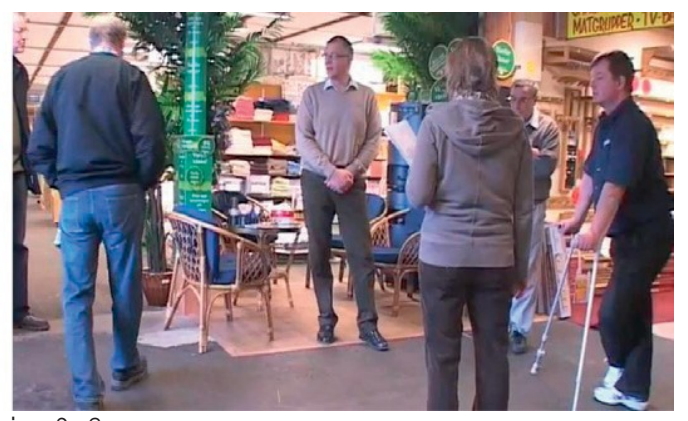

im. 9.2

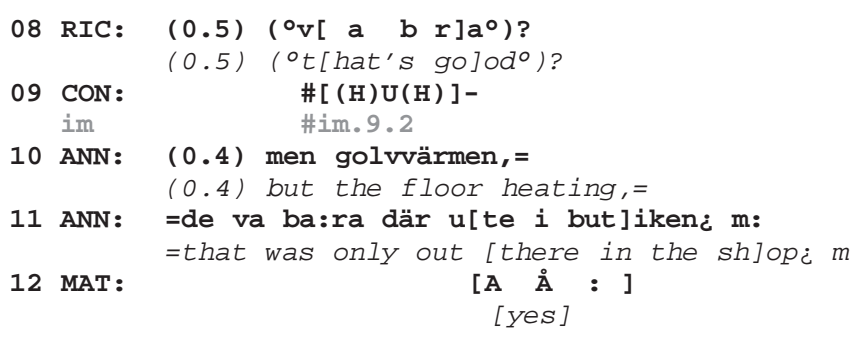

At the beginning of the fragment, Richard asks about the presence of “ 'ground insulation" at their current location(1--2), to which Lars provides a negative answer and an account (3--5). As Lars' turn reaches projectable completion (5), Richard begins to turn and walk away (Image 9.1). This means that, as he responds to this piece of news with a change-of-state token (9), he is already walking away, out of the group and in direction of the group's projected trajectory (Image 9.2). Looking down and in front of him, he does not seem to be very receptive as to what the others are doing. And despite the fact that nobody joins him, he continues his walk (Image 9.2). This is very unusual in our data, in which the only other instances of unilateral walking concern marginal or peripheral participants, to which the main participants do not pay attention. But here, the person walking away is the one who has just asked a question and is currently receiving an answer. 
There is evidence that the other participants orient to this behaviour as unusual. As Richard takes his first step, his colleague Conny follows him with his gaze. Conny soon utters a kind of muffled aspirated syllable (line 9 and Image 9.2) that we hear as a display of surprise. What is unexpected, we argue, is the uni-lateral and un-accounted for departure by Richard, who, being directly involved in a question-answer sequence, is one of the main participants in the current participant framework. Thus, Conny orients to this instance of walking away as normatively deviant.

Of course, Richard's deviant behaviour may be designed to achieve something in particular, such as "doing being annoyed"' (cf. Dersley and Wootton, 2001; Llewellyn and Butler, 2011 on “'walk-outs"). This in turn would suggest that a participant's breach of the norms can in fact be competently and purposefully designed to display a particular stance without having to express it explicitly.

\section{Conclusion}

This paper offers empirical evidence of walking as embodied conduct oriented to in a 'seen but unnoticed' way (Garfinkel, 1967:118) by the participants, and systematically organized in close relation with the sequential organization of talk. Walking is a multimodal resource that contributes to the organization of social activities in mobile settings, and to the coordinated and collective formating of actions, of sequences and of turns at talk, in a reflexive and detailed way.

The various excerpts analyzed show that participants orient to emergent moments within sequence closings to make walking away relevant. For instance, at pre-completion or completion of the turn closing a sequence, participants can begin to move on in different mobile formations. All participants may begin to move together, one participant may initiate walking, to be followed by the others, or various participants may progressively begin to walk in a more or less dispersed way. As we have seen, this movement towards sequence closing can be suspended by expansions, increments, add-ons which redefine and renegotiate the possible closings and continue the ongoing activity. In that environment, participants might slow down or stop, and then resume their walking.

This concerted accomplishment has a normative character. This is particularly demonstrated by our last two cases: when projected walking is not immediately performed it can be pursued, and when a participant unilaterally walks away without coordinating his walking with his co-participant, prior to the completion of a conversational sequence, this is oriented to as deviant by other co-participants.

Walking away in this environment does not merely respond to closings but more radically achieves closings. By walking away at what the walker treats as a closing position, (s)he makes this closing recognizable and accountable, thus contributing to it and even achieving it as such. This accounts for the reflexive organization of talking and walking.

This study complements the existing literature on closings in interaction by bringing the moving bodies of the participants into the analysis of how closings are interactionally achieved. It continues the work of unveiling the full richness of activity closings as embodied and emplaced interactional accomplishments. Closing a conversational sequence emerges as a multifaceted accomplishment. In beginning to walk away, participants not only manage and orient to the current state of the emergent turn and conversational sequence, they also manage their mutual availability within a dissolving F-formation (Kendon, 1990), as well as the overall trajectory of the walk in the physical environment.

This paper has sketched the overall gestalt of the phenomenon of walking away at closings. Our work opens up possible topics to be further systematically elaborated. For instance, in a type of activity ("guided tour") which is organized on the basis of a standardized category pair (Sacks, 1992) ("guide"/"guided"), who initiates walking away is consequential in many ways. First, it impacts on the sequential organization of the closing/walking away. Second, it matters for the intelligibility of the activity, the embodiment of relevant membership categories, and the display of their respective rights and obligations. More generally, this raises questions regarding the intertwined relationships between sequentiality, membership categorization and embodiment.

Other issues concern the complex organization of multimodality. Our paper demonstrates the deep interdependecies between talking, walking and other embodied practices in their material environment. Walking practices are interesting at various levels. First, their relevance involves the entire body --and not only gesture and head movement --contributing to the organization of social interaction. Second, they relate to the mobile body, and not only to its static positions. Third, they are clearly interactionally organized within particular activities (such as in walking together). Last, they are timely and sequentially finely tuned with the mobilization of linguistic resources, reflexively contributing to the intelligibility of talk; importantly, methodic walking practices emerge as highly stable across different languages. Our study thus provides further empirical specification to the claim that talk and aspects of bodily behaviour in its environment mutually inform each other for their situated intelligibility.

\section{Acknowledgements}

The Pier corpus was recorded by Fredrik Lundström, and was used as data in Broth and Lundström (2013). The Energy Analysis corpus was recorded by Mathias Broth. The Blandan corpus was recorded by Lorenza Mondada with 
her team at ICAR Lyon. The Archivis corpus was recorded by her and her master students during a fieldwork exercise. The Cooking corpus was recorded by her. The Tourly corpus was recorded by Claire Luciani as part of a project supervised by her.

This paper was presented at the International Workshop on Interaction and Mobility in Linköping in April 2011 and at the 10th EMCA Conference in Fribourg in July 2011 and has benefited from discussions in these events. The paper has been supported by the Department of Culture and Communication, Linköping University, offering an guest professorship to Lorenza Mondada.

\section{Appendix A. Transcript conventions}

Talk has been transcribed according to conventions developed by Gail Jefferson.

An indicative translation is provided line per line, in italics.

Multimodal details have been transcribed according to the following conventions:

** Delimit descriptions of one speaker's actions.

$++\quad$ Delimit descriptions of another speaker's actions.

Etc. For each participant, a specific symbol is used.

*---> Action described continues across subsequent lines.

*--->> Action described continues until and after the end of the excerpt.

---->* Action described continues until the same symbol is reached.

$>$-- Action described begins before the beginning of the excerpt.

.... Preparation of the action.

,,,, $\quad$ Retraction of the action.

cha Participant doing the action is identified in small characters. When s/he is not the current speaker or when the gesture is made during a pause.

im Image; frame grab.

\# Indicates the exact moment at which the frame grab was recorded.

LF Left foot

RF Right foot

\section{References}

Allen-Collinson, J., 2006. Running together: some ethnomethodological considerations. Ethnographic Studies 8, 17--29.

Antaki, C., 2002. "Lovely”: turn-initial high-grade assessments in telephone closings. Discourse Studies 4, 5--23.

Auer, P., 1990. Rhythm in telephone closings. Human Studies 13, 361--392.

Birkner, K., Stukenbrock, A., 2010. Multimodale Ressourcen für Stadtführungen (Multimodal resources in guided visits). In: Costa, M., MüllerJacquier, B. (Eds.), Deutschland als fremde Kultur: Vermittlungsverfahren in Touristenführungen. (Germany as a Foreign Culture: Communicative Procedures in Turistic Guided Visits).Judicium Verlag, München, pp. 214--243.

Bolden, G., 2008. Reopening Russian conversations: the discourse particle---to and the negotiation of interpersonal accountability in closings. Human Communication Research 34 (1), 99--136.

Broth, M., 2009. Seeing through screens, hearing through speakers: managing distant studio space in television control room interaction. Journal of Pragmatics 41 (10), 1998--2016.

Broth, M., Lundström, F., 2013. A walk on the pier. Establishing relevant places in mobile instruction. In: Haddington, P., Mondada, L., Nevile, M. (Eds.), Interaction and Mobility. Mouton de Gruyter, Berlin.

Broth, M., Haddington, P., McIlvenny, P. (Eds.), Mobile Formations in Social Interaction. Special issue of Space and Culture, forthcoming.

Button, G., 1987. Moving out of closings. In: Button, G., Lee, J.R.E. (Eds.), Talk and Social Organisation. Multilingual Matters, Clevedon, pp. 101-151.

Button, G., Casey, N., 1985. Topic nomination and pursuit. Human Studies 9, 3--55.

De Stefani, E., 2006. Le chiusure conversazionali nell'interazione al banco di un supermercato (Closings in interactions at the counter of a supermarket). In: Bürki, Y., De Stefani, E. (Eds.), Trascrivere la lingua. Dalla filologia all'analisi conversazionale. (Transcribing Language. From Philology to Conversation Analysis).Peter Lang, Bern, pp. 369--403.

De Stefani, E., 2010. Reference as an interactively and multimodally accomplished practice: organizing spatial reorientation in guided tours. In: Pettorino, M., Giannini, A., Chiari, I., Dovetto, F. (Eds.), Spoken Communication. Cambridge Scholars Publishing, Newcastle upon Tyne, pp. 137--170.

De Stefani, E., 2012. The collaborative organisation of next actions in a semiotically rich environment: shopping as a couple. In: Haddington, P., Mondada, L., Nevile, M. (Eds.), Interaction and Mobility. de Gruyter, Berlin.

Deppermann, A., Schmitt, R., Mondada, L., 2010. Agenda and emergence: contingent and planned activities in a meeting. Journal of Pragmatics $42(6), 1700--1718$. 
Dersley, I., Wootton, A., 2001. In the heat of the sequence: interactional features preceding walkouts from argumentative talk. Language in Society 30, 611--638.

Ford, C.E., Fox, B.A., Thompson, S.A., 1996. Practices in the construction of turns: the "TCU' revisited. Pragmatics 6 (3), $427--454$.

Ford, C.E., Fox, B.A., Thompson, S.A., 2002. Constituency and the grammar of turn increments. In: Ford, C.E., Fox, B.A., Thompson, S.A. (Eds.), The Language of Turn and Sequence. Oxford University Press, Oxford, pp. 14--38.

Garfinkel, H., 1967. Studies in Ethnomethodology. Prentice-Hall, Englewood Cliffs, NJ.

Garfinkel, H., Sacks, H., 1970. On formal structures of practical actions. In: McKinney, J.D., Tiryakian, E.A. (Eds.), Theoretical Sociology. Appleton-Century Crofts, New York, pp. 337--366.

Goffman, E., 1971. Relations in Public: Microstudies of the Public Order. Harmondsworth, Penguin.

Goffman, E., 1981. Forms of Talk. Basil Blackwell, Oxford.

Goldberg, J.A., 2004. The amplitude shift mechanism in conversational closing sequences. In: Lerner, G.H. (Ed.), Conversation Analysis: Studies from the First Generation. Amsterdam, Benjamins, pp. 257--297.

Goodwin, C., 1981. Conversational Organization: Interaction between Speakers and Hearers. Academic Press, New York.

Goodwin, C., 2000. Action and embodiment within situated human interaction. Journal of Pragmatics 32, 1489--1522.

Goodwin, C., Goodwin, M.H., 1996. Seeing as situated activity: formulating planes. In: Engeström, Y., Middleton, D. (Eds.), Cognition and Communication at Work. Cambridge University Press, Cambridge, pp. 61--95.

Haddington, P., Mondada, L., Nevile, M. (Eds.), 2013. Interaction and Mobility. de Gruyter, Berlin.

Hausendorf, H., Mondada, L., Schmitt, R. (Eds.), 2012. Raum als interaktive Resource (Space as an Interactional Resource). Narr, Tübingen.

Heath, C., 1986. Body Movement and Speech in Medical Interaction. Cambridge University Press, Cambridge.

Heritage, J., 1984. Garfinkel and Ethnomethodology. Polity Press, Cambridge.

Jefferson, G., 1978. Sequential aspects of storytelling in conversation. In: Schenkein, J. (Ed.), Studies in the Organization of Conversational Interaction. Academic Press, New York, pp. 219--248.

Kendon, A., 1990. Conducting Interaction: Patterns of Behaviour in Focussed Interaction. Cambridge University Press, Cambridge.

LeBaron, C., Jones, S., 2002. Closing up closings: showing the relevance of the social and material surround to the completion of an interaction. Journal of Communication 53 (3), 542--565.

Linell, P., 2009. Rethinking Language, Mind, and World Dialogically. Interactional and Contextual Theories of Human Sense-making. Information Age Publishing, Charlotte, NC.

Llewellyn, N., Butler, C.W., 2011. Walking out on air. Research on Language \& Social Interaction 44 (1), $44--64$.

Luff, P., Heath, C., 1998. Mobility in collaboration. In: Proceedings of CSCW 98. ACM Press, New York.

McIlvenny, P., Broth, M., Haddington, P. (Eds.), 2009. Communicating Place, Space and Mobility Special Issue of Journal of Pragmatics, 41 (10).

Modaff, D.P., 2003. Body movement in the transition from opening to task in doctor--patient interviews. In: Glenn, P., LeBaron, C.D., Mandelbaum, J. (Eds.), Studies in Language and Social Interaction: In honor of Robert Hopper. Lawrence Erlbaum, Mahweh, NJ, pp. 411--422.

Mondada, L., 2006. Participants' online analysis and multimodal practices: projecting the end of the turn and the closing of the sequence. Discourse Studies 8, 117--129.

Mondada, L., 2009. Emergent focused interactions in public places: a systematic analysis of the multimodal achievement of a common interactional space. Journal of Pragmatics 41 (10), 1977--1997.

Mondada, L., Schmitt, R. (Eds.), 2010. Situationseröffnungen: Zur multimodalen Herstellung fokussierter Interaktion (Openings of Situations: About the Multimodal Establishment of Focused Interaction). Narr, Tübingen.

Pekarek Doehler, S., De Stefani, E., Horlacher, A.-S., 2011. The grammar of closings: the use of dislocated constructions as closing initiators in French talk-in-interaction. Nottingham French Studies 50 (2), 51--76.

Pitsch,K., 2012. Museumsexponat, Alltagsobjekt oderTurngerät? Zur Konstitution von Objekten im Interaktion. (Museum exhibit, everyday object or gym equipment? About the constitution of objects in interaction). In: Hausendorf, H., Mondada, L., Schmitt, R. (Eds.), Raum als interaktive Resource (Space as an Interactional Resource).Narr, Tübingen.

Relieu, M., 1999. Parler en marchant: Pour une écologie dynamique des échanges de paroles (Talking while walking: towards a dynamic ecology of verbal exchanges). Langage \& société 89, 37--67.

Robinson, J.D., Stivers, T., 2001. Achieving activity transitions in primary-care encounters: from history taking to physical examination. Human Communication Research 27, 253--298.

Ryave, A.L., Schenkein, J.N., 1974. Notes on the art of walking. In: Turner, R. (Ed.), Ethnomethodology. Harmondsworth, Penguin, pp. 265--274. Sacks, H., 1992. Lectures on Conversation [1964--72] (2 Vols.) Basil Blackwell, Oxford.

Sacks, H., Schegloff, E.A., Jefferson, G., 1974. A simplest systematics for the organization of turn-taking for conversation. Language 50, 696--735. Schegloff, E.A., Sacks, H., 1973. Opening up closings. Semiotica 8, 289--327., http://www.gespraechsforschung-ozs.de/.

Streeck, J., Goodwin, C., LeBaron, C., 2011. Embodied Interaction: Language and Body in the Material World. Cambridge University Press, Cambridge.

Sudnow, D., 1972. Temporal parameters of interpersonal observation. In: Sudnow, D. (Ed.), Studies in Social Interaction. Free Press, New York, pp. 259--279.

vom Lehn, D., 2013. Withdrawing from exhibits: the interactional organisation of museum visits. In: Haddington, P., Mondada, L., Nevile, M. (Eds.), Interaction and Mobility. de Gruyter, Berlin.

Watson, R., 2005. The visibility arrangements of urban public space: conceptual resources and methodological issues in analysing pedestrian movements. Communication and Cognition 38 (3--4), 201--226.

Wright, M., 2011. The phonetics--interaction interface in the initiation of closings in everyday English telephone calls. Journal of Pragmatics 43 (4), 1080--1099. 